\title{
Acetylene Polycyclotrimerization: Synthesis and Characterization of Ferrocene-Containing Hyperbranched Polyarylenes
}

Jianbing Shi, ${ }^{\dagger}$ Bin Tong, ${ }^{\dagger}$ Wei Zhao, ${ }^{\dagger}$ Jinbo Shen, ${ }^{\dagger}$ Junge Zhi, ${ }^{\ddagger}$ Yuping Dong, ${ }^{*}{ }^{\dagger}$ Matthias Häußler,${ }^{\S}$ Jacky W. Y. Lam, ${ }^{\S}$ and Ben Zhong Tang ${ }^{*, \S}$

${ }^{\dagger}$ College of Materials Science \& Engineering, ${ }^{\star}$ College of Science, Beijing Institute of Technology, Beijing 100081, China, and ${ }^{\S}$ Department of Chemistry, The Hong Kong University of Science \& Technology, Clear Water Bay, Kowloon, Hong Kong, China

\section{General Information}

Toluene was distilled over calcium hydride under nitrogen before use. Triethylamine was distilled under normal pressure and kept over potassium hydroxide under nitrogen. Dichloromethane (DCM) was predried over calcium hydride and distilled under nitrogen. 4,4'-Diiodobiphenyl (C), 2-methyl-3butyn-2-ol (D), ferrocenecarboxaldehyde (F), potassium t-butoxide, triphenylphosphine, copper(I) iodide, bis(triphenylphosphine) palladium(II) chloride, and tetrabutylammonium hexafluorophophate were purchased from Aldrich and used as received. Dicarbonylcyclopentadienylcobalt (Aldrich) was diluted with toluene to a concentration of $10 \mathrm{mg} / \mathrm{mL}$ by a standard Schlenk technology under nitrogen. 4-Bromobenzyltriphenylphosphonium bromide $(\mathrm{G})$ was prepared according to published experimental procedures. ${ }^{1} \quad$ All other regents and solvents were purchased from Beijing Reagent Company and used without further purification. 
Molecular weights and polydispersity indexes of the ferrocene-containing hyperbranched polyarylenes were estimated by a Waters 2414 GPC system equipped with a RI detector, using monodisperse linear polystyrenes as calibration standards and THF as eluent at a flow rate of $1.0 \mathrm{~mL} / \mathrm{min}$. IR spectra were measured on a NEXUS-470 FTIR (Nicolet) spectrophotometer using KBr disks. NMR spectra were recorded on a Bruker ARX-400 spectrometer using deuterated chloroform or dimethyl sulfoxide (DMSO) as solvent and tetramethylsilane (TMS) as internal reference. UV absorption spectra were measured on a Hitachi U-2800 spectrophotometer. Fluorescence spectra were recorded on a Varian Cary Eclipse spectrofluorometer. Thermogravimetric analyses (TGA) were carried out on a Universal V2.6D TA Instruments at a heating rate of $10^{\circ} \mathrm{C} / \mathrm{min}$ under nitrogen. Mass spectra were record on a GCT-MS Micromass UK spectrometer operating in electron ionization (EI) mode. Elemental analyses were carried out with an Elementar Vario EL analyzer.

Cyclic voltammetry experiments were performed on a CHI660A electrochemical workstation. All measurements were conducted at room temperature with a conventional three-electrode configuration. The working electrode was a platinum wire with a $2 \mathrm{~mm}$ diameter, the reference electrode was a saturated calomel electrode, and the counter electrode was a platinum sheet. Polymer solution in DCM was approximately $1 \mathrm{mM}$ in concentration, containing $0.1 \mathrm{M}$ of $\left[\mathrm{NBu}_{4}\right]\left[\mathrm{PF}_{6}\right]$ as supporting electrolyte. Cyclic voltammograms were measured at a scan rate of $0.1 \mathrm{~V} / \mathrm{s} . \quad E_{1 / 2}$ values were determined as $\left(E_{\mathrm{pa}}+\right.$ $\left.E_{\mathrm{pc}}\right) / 2$, where $E_{\mathrm{pa}}$ and $E_{\mathrm{pc}}$ are anodic and cathodic peak potentials, respectively.

\section{Monomer Synthesis}

Preparation of 4,4'-Bis(3-hydroxy-3-dimethyl-1-propynyl)biphenyl (E). Into a three-necked round-bottom flask were added $0.812 \mathrm{~g}$ of $\mathrm{C}$ ( $2 \mathrm{mmol}), 0.07 \mathrm{~g}$ of bis(triphenylphosphine)palladium(II) chloride $(0.1 \mathrm{mmol}), 0.052 \mathrm{~g}$ of triphenylphosphine $(0.2 \mathrm{mmol})$, and $0.038 \mathrm{~g}$ of copper(I) iodide $(0.2$ 
mmol) under argon. Into the solution, $100 \mathrm{~mL}$ of triethylamine and $0.378 \mathrm{~g}$ of $\mathrm{D}(4.5 \mathrm{mmol})$ were injected. The resultant mixture was stirred at room temperature for $24 \mathrm{~h}$ and the solvent was removed at a reduced pressure. The residual solid was dissolved in DCM and washed with a solution of $\mathrm{NH}_{4} \mathrm{Cl}$. The organic layer was dried over $\mathrm{MgSO}_{4}$ and filtered. The solvent was removed at a reduced pressure to give a residual solid, which was purified by silica gel column chromatography using $n$-hexane/ethyl acetate $(6: 4 \mathrm{v} / \mathrm{v})$ as eluent to give a white solid of $\mathrm{E}$ in $89.7 \%$ yield $(0.571 \mathrm{~g})$.

Synthesis of 4,4'-Diethynylbiphenyl (A). Into a three-necked round-bottom flask were added a toluene solution of $\mathrm{E}(0.637 \mathrm{~g}, 2 \mathrm{mmol})$ and finely powered $\mathrm{NaOH}(0.4 \mathrm{~g})$ under argon. The mixture was refluxed for $3 \mathrm{~h}$ and then filtered. The solvent was removed at a reduced pressure. The residue was purified by silica gel column chromatography using $n$-hexane/DCM $(8: 2 \mathrm{v} / \mathrm{v})$ as eluent to give a pale yellow solid of A in 93.7\% yield $(0.379 \mathrm{~g}) . \quad{ }^{1} \mathrm{H}$ NMR (DMSO- $\left.d_{6}\right): 7.73(\mathrm{~d}, 4 \mathrm{H}, \mathrm{J}=8.4 \mathrm{~Hz}), 7.58$ $(\mathrm{d}, 4 \mathrm{H}, \mathrm{J}=8.4 \mathrm{~Hz}), 4.29(\mathrm{~s}, 2 \mathrm{H}) . \quad{ }^{1} \mathrm{H} \mathrm{NMR}\left(\mathrm{CDCl}_{3}\right): 7.57(\mathrm{~d}, 4 \mathrm{H}, \mathrm{J}=7.60 \mathrm{~Hz}), 7.54(\mathrm{~d}, 4 \mathrm{H}, \mathrm{J}=7.44$

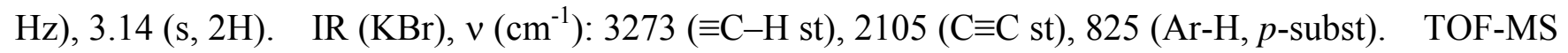
(EI): $\mathrm{m} / \mathrm{z}$ Calcd. for $\mathrm{C}_{16} \mathrm{H}_{10}$ 202.25; Found $202\left(\mathrm{M}^{+}\right)$. Elemental analysis: Calcd. for $\mathrm{C}_{16} \mathrm{H}_{10}$ : C 95.02, H 4.98; Found 94.96, H 5.23.

Preparation of 1-Ferrocenyl-2-(4-bromophenyl)ethene (H). Into a three-necked round-bottom flask in an ice-water bath were added $10.244 \mathrm{~g}$ of G (20 mmol; dispersed in $50 \mathrm{~mL}$ of anhydrous toluene) and $3.366 \mathrm{~g}$ of potassium $t$-butoxide $(30 \mathrm{mmol})$ with stirring under argon. After $30 \mathrm{~min}$, the solution became intensely orange colored, into which a solution of $2.855 \mathrm{~g}$ of $\mathrm{F}(13.33 \mathrm{mmol})$ in $40 \mathrm{~mL}$ of anhydrous toluene was added dropwise. The mixture was stirred at room temperature overnight and the solvent was then removed at a reduced pressure. A residual red solid was dissolved in DCM and washed with an aqueous solution of ammonium chloride and potassium carbonate. The organic layer 
was dried on $\mathrm{MgSO}_{4}$ and filtered. The solvent was removed at a reduced pressure. The solid residue was purified by silica gel column chromatography using hexane/DCM (8:2 v/v) as eluent. Compound $\mathrm{H}$ was obtained as a mixture of $E / Z$ isomers in $93.7 \%$ yield $(4.584 \mathrm{~g})$. By crystallization from hexane, crystals of $\mathrm{H}(E)$ were isolated, with its $Z$ isomer left in the solution.

$Z \rightarrow E$ Isomerization of 1-Ferrocenyl-2-(4-bromophenyl)ethene. To a hexane solution of $H(Z)$ was added a crystal of iodine. The mixture was refluxed for $3 \mathrm{~h}$, during which the reaction was monitored by thin layer chromatography. After completion of the reaction, the solvent was removed at a reduced pressure. The residual solid was dissolved in DCM and washed with an aqueous solution of sodium thiosulfate. The organic layer was dried over $\mathrm{MgSO}_{4}$ and filtered. The solvent was removed at a reduced pressure. $\quad$ Pure $\mathrm{H}(E)$ was obtained in quantitative yield. ${ }^{1} \mathrm{H}$ NMR $\left(\mathrm{CDCl}_{3}\right): 7.44(\mathrm{~d}, 2 \mathrm{H}, \mathrm{J}=8$ Hz), $7.28(\mathrm{~d}, 2 \mathrm{H}, \mathrm{J}=8 \mathrm{~Hz}), 6.86(\mathrm{~d}, 1 \mathrm{H}, \mathrm{J}=16 \mathrm{~Hz}), 6.59(\mathrm{~d}, 1 \mathrm{H}, \mathrm{J}=16 \mathrm{~Hz}), 4.50(\mathrm{~s}, 2 \mathrm{H}), 4.34(\mathrm{~s}, 2 \mathrm{H})$, $4.17(\mathrm{~s}, 5 \mathrm{H}) . \quad \mathrm{IR}(\mathrm{KBr}), v\left(\mathrm{~cm}^{-1}\right): 1632(\mathrm{C}=\mathrm{C} \mathrm{st}), 1403(\mathrm{Fc}), 1003(\mathrm{Fc}), 961$ (=C-H, E-isomer $), 806$ (Ar-H, p-subst).

Preparation of 4-[4-((E)-2-Ferrocenylvinyl)phenyl]-2-methyl-3-butyn-2-ol (I). Into a threenecked, round-bottomed, flame-dried flask were added $0.734 \mathrm{~g}$ of $\mathrm{H}(E)(2 \mathrm{mmol}), 0.07 \mathrm{~g}$ of bis(triphenylphosphine)palladium(II) chloride $(0.1 \mathrm{mmol}), 0.052 \mathrm{~g}$ of triphenylphosphine $(0.2 \mathrm{mmol})$, and $0.038 \mathrm{~g}$ of copper(I) iodide $(0.2 \mathrm{mmol})$ under argon. Into the solution, $100 \mathrm{~mL}$ of triethylamine and $0.210 \mathrm{~g}$ of $\mathrm{D}(2.5 \mathrm{mmol})$ were injected. The resultant mixture was stirred at $50{ }^{\circ} \mathrm{C}$ for $24 \mathrm{~h}$. The solvent was removed at a reduced pressure and the residual solid was dissolved in DCM and washed with a solution of $\mathrm{NH}_{4} \mathrm{Cl}$. The organic layer was dried over $\mathrm{MgSO}_{4}$ and filtered. Evaporation of solvent under reduced pressure gave a residual solid, which was purified by silica gel column using $n$-hexane/ethyl acetate $(8: 2 \mathrm{v} / \mathrm{v})$ as eluent to afford an orange solid of I in $92.6 \%$ yield $(0.686 \mathrm{~g})$. 
Synthesis of (E)-1-Ferrocenyl-2-(4-ethynylphenyl)ethene (B). In a three-necked, round-bottomed, flame-dried flask were added a toluene solution of $0.741 \mathrm{~g}$ of I ( $2 \mathrm{mmol})$ and $0.4 \mathrm{~g}$ of finely powered $\mathrm{NaOH}$ under argon. The mixture was refluxed for $3 \mathrm{~h}$ and then filtered. The solvent was removed at a reduced pressure. The residual solid was purified by silica gel column chromatography using $n$-hexane/DCM $(8: 2 \mathrm{v} / \mathrm{v})$ as eluent to give a red solid of $\mathrm{B}$ in $97.0 \%$ yield $(0.606 \mathrm{~g}) .{ }^{1} \mathrm{H}$ NMR (DMSO-d $): 7.49$ (d, 2H, J = 8.3 Hz), $7.42(\mathrm{~d}, 2 \mathrm{H}, \mathrm{J}=8.3 \mathrm{~Hz}), 7.05$ (d, 1H, J = 16.2 Hz), 6.77 (d, 1H, J $=16.2 \mathrm{~Hz}), 4.57(\mathrm{~s}, 2 \mathrm{H}), 4.34(\mathrm{~s}, 2 \mathrm{H}), 4.14(\mathrm{~s}, 5 \mathrm{H}), 4.21(\mathrm{~s}, 1 \mathrm{H}) . \quad{ }^{1} \mathrm{H} \mathrm{NMR}\left(\mathrm{CDCl}_{3}\right): 7.46(\mathrm{~d}, 2 \mathrm{H}, \mathrm{J}=8$ Hz), 7.37 (d, 2H, J = $8 \mathrm{~Hz}), 6.90(\mathrm{~d}, 1 \mathrm{H}, \mathrm{J}=16 \mathrm{~Hz}), 6.63(\mathrm{~d}, 1 \mathrm{H}, \mathrm{J}=16 \mathrm{~Hz}), 4.55(\mathrm{~s}, 2 \mathrm{H}), 4.38(\mathrm{~s}, 2 \mathrm{H})$, $4.20(\mathrm{~s}, 5 \mathrm{H}), 3.13(\mathrm{~s}, 1 \mathrm{H}) . \quad \mathrm{IR}(\mathrm{KBr}), v\left(\mathrm{~cm}^{-1}\right): 3264(\equiv \mathrm{C}-\mathrm{H} \mathrm{st}), 2099(\mathrm{C} \equiv \mathrm{C} \mathrm{st}), 1632(\mathrm{C}=\mathrm{C} \mathrm{st}), 1691$ (Fc), 1411 (Fc), 1026 (Fc), 968 (=C-H, E-isomer), 814 (Ar-H, p-subst). TOF-MS (EI): m/z Calcd. for $\mathrm{C}_{20} \mathrm{H}_{16} \mathrm{Fe} 312.19$; Found $312\left(\mathrm{M}^{+}\right)$. Element analysis: Calcd. for $\mathrm{C}_{20} \mathrm{H}_{16} \mathrm{Fe}$ : C 76.95, H 5.17; Found C 76.83, H 5.26.

\section{Polymerization Reaction}

Experimental Procedures. Into a fire-baked and moisture-excluded Schlenk tube was added predetermined amounts of diyne A and monoyne B in a glovebox. An appropriate amount of toluene was added to the tube, followed by addition of a solution of $\mathrm{CpCo}(\mathrm{CO})_{2}$ in toluene. The mixture was irradiated under stirring with a $200 \mathrm{~W} \mathrm{Hg}$ lamp (operating at $100 \mathrm{~V}$ ) placed $\sim 5 \mathrm{~cm}$ away from the center of the Schlenk tube. The irradiation was continued for a specified time at $65{ }^{\circ} \mathrm{C}$. The polymerization reaction was terminated by the addition of a small amount of methanol. The mixture was dropped into $250 \mathrm{~mL}$ methanol through a cotton filter under stirring. The precipitate was collected and redissolved in chloroform. The resultant solution was filtered and poured into hexane to further purify the polymer 
product. The precipitate was collected, washed sequentially with methanol and hexane, and then dried under vacuum to a constant weight.

Characterization Data for P2. ${ }^{1} \mathrm{H}$ NMR (DMSO- $\left.d_{6}\right): 6.77-8.07(\mathrm{Ar}-\mathrm{H}$ and $\mathrm{CH}=\mathrm{CH}), 4.58(\mathrm{Cp})$, $4.35(\mathrm{Cp}), 4.29(\mathrm{C} \equiv \mathrm{CH}), 4.16(\mathrm{Cp}) . \quad \mathrm{IR}(\mathrm{KBr}), v\left(\mathrm{~cm}^{-1}\right): 3285(\equiv \mathrm{C}-\mathrm{H} \mathrm{st}), 2104(\mathrm{C} \equiv \mathrm{C} \mathrm{st}), 1628(\mathrm{C}=\mathrm{C} \mathrm{st})$, $1411(\mathrm{Fc}), 1026$ (Fc), 956 (=C-H, E-isomer), 814 (Ar-H, p-subst).

\section{Reference}

(1) Rodriguez, J. G.; Gayo, M.; Fonseca, I. J. Organomet. Chem. 1997, 534, 38.

Table S1. Electrochemical Data for Mixtures of Diyne A and Monoyne B ${ }^{a}$

\begin{tabular}{cccccccc}
\hline no. & {$[\mathrm{A}]:[\mathrm{B}]$} & $f_{\mathrm{B}}$ & $i_{\mathrm{p}}{ }^{\mathrm{a}}(\mu \mathrm{A})$ & $i_{\mathrm{p}}{ }^{\mathrm{c}}(\mu \mathrm{A})$ & $E_{\mathrm{p}}{ }^{\mathrm{a}}(\mathrm{V})$ & $E_{\mathrm{p}}{ }^{\mathrm{c}}(\mathrm{V})$ & $E_{1 / 2}(\mathrm{~V})$ \\
\hline 1 & $0.0: 1.0$ & 1.00 & 8.593 & -8.491 & 0.506 & 0.407 & 0.457 \\
2 & $0.5: 1.0$ & 0.67 & 5.886 & -5.895 & 0.492 & 0.404 & 0.448 \\
3 & $1.0: 1.0$ & 0.50 & 4.392 & -4.368 & 0.495 & 0.408 & 0.452 \\
4 & $3.0: 1.0$ & 0.25 & 2.212 & -2.317 & 0.495 & 0.423 & 0.459 \\
5 & $6.0: 1.0$ & 0.14 & 1.233 & -1.332 & 0.485 & 0.413 & 0.449 \\
6 & $10.0: 1.0$ & 0.09 & 0.722 & -0.844 & 0.495 & 0.423 & 0.459
\end{tabular}

${ }^{a}$ For definitions of the symbols, see related footnotes given in Table 2. 

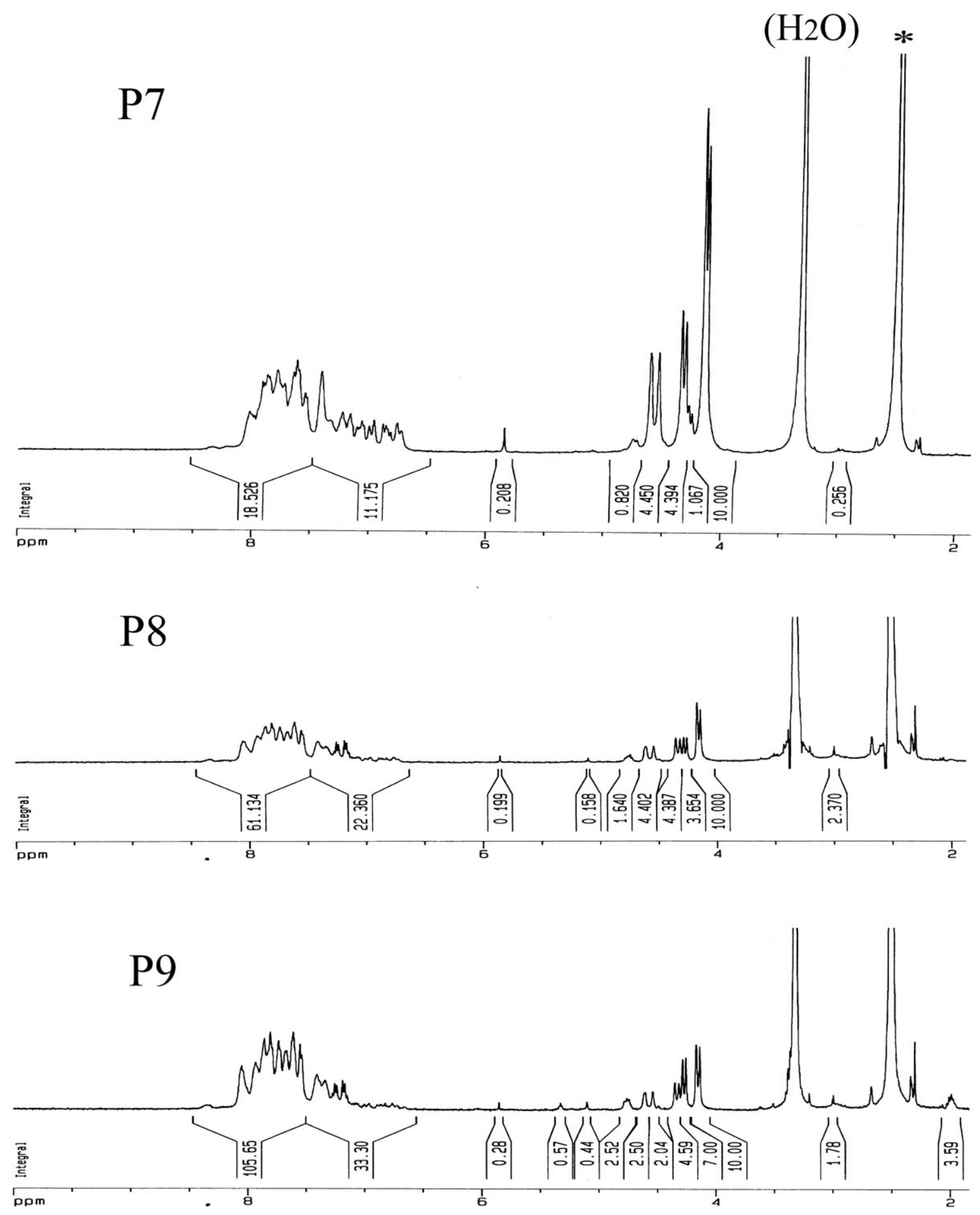

Figure S1. ${ }^{1} \mathrm{H}$ NMR spectra of DMSO- $d_{6}$ solutions of hyperbranched polyarylenes (samples taken from Table 1, nos. 7-9). 